\title{
The Glass Transition Temperatures of PMMA Grafted Natural Rubber Toughened Epoxy/Layered Silicate Nanocomposite
}

\author{
Nor Yuliana Yuhana \\ Research Centre for Sustainable Process Technology, Department of Chemical Engineering, \\ Faculty of Engineering and Built Environment, University Kebangsaan Malaysia, \\ 43600 Bangi, Selangor, Malaysia
}

\begin{abstract}
The glass transition temperature of ternary systems containing epoxy, PMMA grafted natural rubber and organic chemically modified montmorillonite (Cloisite 30B) were studied. Differential Scanning Calorimetry (DSC), Transmission Electron Microscopy (TEM), Infrared spectroscopy (FTIR) and Wide Angle X-ray Diffraction (WAXD) analysis were used. The following 4 materials were cured at $40^{\circ} \mathrm{C}$ for $20 \mathrm{~h}$ with and without postcuring at $125^{\circ} \mathrm{C}$ for $3 \mathrm{~h}$. The samples were cured unmodified epoxy, cured toughened epoxy, cured unmodified epoxy/cloisite 30B nanocomposites and cured toughened epoxy/cloisite 30B nanocomposites. Mixing process was performed by mechanical stirring. Poly (etheramine) was used as the curing agent. From the DSC analys is we found that the postcured samples possessed higher onset of glass transition temperature $\left(\mathrm{T}_{\mathrm{g}}\right)$. The presence of rubber can either increase or decrease the $\mathrm{T}_{\mathrm{g}}$ of epoxy-rubber blend. The addition of $5 \mathrm{phr}$ cloisite $30 \mathrm{~B}$, however, does not change the $\mathrm{T}_{\mathrm{g}}$, compared to the neat epoxy. The increase in $\mathrm{T}_{\mathrm{g}}$ was observed for rubber toughened epoxy clay nanocomposite. The TEM images show the agglomeration of silicate and intercalated structure of silicate in binary and ternary nanocomposites. The WAXD results indicate the presence of crystalline structure in both unpostcured and postcured epoxy.
\end{abstract}

Key words: Polymer processing, nanocomposite, epoxy, rubber, glass transition temperature, DSC

\section{INTRODUCTION}

Epoxy/layered silicate nanocomposites exhibit improved thermal, barrier and mechanical properties (Becker and Simon, 2005). Meanwhile, the incorporation of dispersed rubbery particles in a layered silicate/epoxy nanocomposite has received significant attention (Liu et al., 2004; Froehlich et al., 2004; Balakrishnan and Raghavan, 2004; Balakrishnan et al., 2005; Ratna et al., 2003; Becker et al., 2005).

It is often stated that the layered silicate can increase the glass transition Temperature $\left(\mathrm{T}_{\mathrm{g}}\right)$ by restricting the epoxy chain mobility. They can also reduce the $\mathrm{T}_{\mathrm{g}}$ due to the presence of hydroxyl group in unmodified mica and acidic onium ion in organically modified silicate which both can act as catalyst for epoxy homopolymerization (Becker et al., 2003; Froehlich et al., 2004). If this happens, the unreacted curing agent will plasticize the matrix. Kinloch and Taylor (2003) concluded that intercalated structure of silicate can improve the $\mathrm{T}_{\mathrm{g}}$ (Kinloch and Taylor, 2003). Becker et al. (2003) found that increasing organoclay concentration is steadily decreased $\mathrm{T}_{\mathrm{g}}$.

In literatures, $T_{g}$ can be increased by the presence of bulky side groups, polar groups, double bonds and aromatic groups. The increase in molecular weight can also raise the $\mathrm{T}_{\mathrm{g}}$. A high density of branches and crosslinks can reduce the chain mobility and increase the $\mathrm{T}_{\mathrm{g}}$ (Callister et al., 2007).

The incorporation of dispersed rubbery particles in a layered silicate/epoxy nanocomposite has received significant attention (Becker and Simon, 2005; Liu et al., 2004; Froehlich et al., 2004; Balakrishnan and Raghavan, 2004; Balakrishnan et al., 2005; Ratna et al., 2003). In this study, we report the effect of postcuring process on morphology and glass transition temperature of cured PMMA grafted natural rubber toughened epoxy layered silicate nanocomposite.

\section{MATERIALS AND METHODS}

Diglycidyl Ether Bisphenol A (DGEBA) epoxy resin, Epikote 828 was obtained from hexion specialty chemicals, Korea. The epoxide equivalent weight was $187 \mathrm{~g} / \mathrm{mol}$. The liquid curing agent, baxxodur TMEC301 (Formerly known as polyetheramine D230) was supplied by BASF. The composition is alpha-(2-aminomethylethyl)-omega-(2aminomethylethoxy)-poly (oxy (methyl-1, 2-ethanediyl)). PMMA-grafted natural rubber megatex 30 was gained 
Table 1: Composition of prepared samples Weight of component $(\mathrm{g})$

\begin{tabular}{llcc} 
& \multicolumn{2}{l}{ Weight of component (g) } & \\
Name of sample & Epikote 828 & Megatex 30 & Cloisite 30B \\
\hline Epoxy & 100 & 0 & 0 \\
Epoxy-5 MG30 & 100 & 5 & 0 \\
Epoxy-5 30B & 100 & 0 & 5 \\
Epoxy-5MG30-5 30B & 100 & 5 & 5 \\
\hline
\end{tabular}

from green HPSP (M) Sdn. Bhd. The organically modified montmorillonite utilized was cloisite 30B, purchased from Southern Clay Products, USA. The composition of the modifier is bis (hydroxyl ethyl) methyl tallow alkyl ammonium salts with montmorillonite.

Sample preparation by mechanical stirring: The compositions of the 4 prepared systems are given in Table 1. One hundred grams of bisphenol A diglycidyl ether were added to a stainless steel cup. The sample was heated to about $55^{\circ} \mathrm{C}$ by using a hot plate. This was followed by the addition of cloisite $30 \mathrm{~B}$ or latex and mechanical stirring at about $50 \mathrm{rpm}$ for about $1 \mathrm{~h}$. A stoichiometric amount of the liquid curing agent was then added and stirred for about 10 min. For the ternary system the natural rubber in latex was added after $30 \mathrm{~min}$ of mixing cloisite $30 \mathrm{~B}$ with the epoxy and the mixture was stirred for another $30 \mathrm{~min}$ at 50-70 $\mathrm{rpm}$. The total mixing duration of the ternary system was about $1 \mathrm{~h}$. The mixture was then cured at $40^{\circ} \mathrm{C}$ for $20 \mathrm{~h}$ without and with postcuring at $125^{\circ} \mathrm{C}$ for $3 \mathrm{~h}$, respectively in a convection oven. The samples were then cooled in a dessicator at room temperature before being characterized.

Differential scanning calorimetry analysis: The glass transition temperature of cured samples was determined by using Mettler Toledo DSC $822^{\mathrm{e}}$. First, the sample was heated at $10^{\circ} \mathrm{C} \mathrm{min}^{-1}$ from $25-170^{\circ} \mathrm{C}$. The sample was maintained at that temperature for approximately $2 \mathrm{~min}$ and then it was cooled to $-20^{\circ} \mathrm{C}$ at the rate of $20^{\circ} \mathrm{C}$ $\min ^{-1}$ to remove any thermal history. Finally, the sample was re-scanned using a modulated heating programme as described above twice.

Fourier Transform Infrared Spectroscopy (FTIR): Infrared analysis of the cured epoxy films was carried out using a Nicolet 6700 by thermo scientific. In this report, spectra are presented in the range between 4000 and $800 \mathrm{~cm}^{-1}$.

Transmission electron microscopy: The samples containing rubber were stained with osmium tetroxide for $1 \mathrm{~h}$ before cutting with a reichert ultracute ultramicrotome using a glass knife at room temperature. The $70-90 \mathrm{~nm}$ thick samples were collected on hexagonal 200 mesh copper grids and the micrographs were obtained from Philips TEM Model CM12 by soft imaging viewer software.

X-ray diffraction: To study the dispersion of cloisite $30 \mathrm{~B}$ inside the epoxy, X-ray diffraction was conducted at room temperature, employing a Bruker AXS D8 advance X-ray diffractometer. The X-ray beam was copper-filtered and radiation generated at operating conditions of $40 \mathrm{kV}$ and $40 \mathrm{~mA}$. The X-ray data were obtained from $2.3-10^{\circ}(2 \theta)$ at a scan rate of $0.025 \% \mathrm{~min}$. Thin specimens about $1 \mathrm{~mm}$ thick were analyzed. Cloisite $30 \mathrm{~B}$ was also characterized to measure the initial dspacing. The graphs were analyzed utilizing diffrac plus (Release 2005) and EVA Version 11 Rev. 0 supplied by Bruker advance X-ray solutions.

\section{RESULTS AND DISCUSSION}

Differential scanning calorimetry analysis: It seems that postcuring could eliminate the existence of enthalpy of relaxation during the first heating scan. This can be observed in Fig. 1 where the presence of enthalpy of relaxation for epoxy cured at room temperature (Yuhana et al., 2012) and when the sample was cured at $40^{\circ} \mathrm{C}$ for $20 \mathrm{~h}$. The onset of $\mathrm{T}_{\mathrm{g}}$ is about $55^{\circ} \mathrm{C}$. As for the postcured epoxy sample, the onset of $\mathrm{T}_{\mathrm{g}}$ of epoxy is about $70^{\circ} \mathrm{C}$. The existence of enthalpy of relaxation could be related to physical aging. The enthalpy of relaxation could be observed for all unpostcured samples during the first heating scan. The clear region for $T_{g}$, could be analysed during the second heating step. The $T_{g}$ regions are given in Fig. 2 and 3 for unpostcured and postcured, respectively with the estimated onset of glass transition temperature. The onset of $T_{g}$ for samples cured at $40^{\circ} \mathrm{C}$ for $20 \mathrm{~h}$ is given in Fig. 2. It seems that the onset of $\mathrm{T}_{\mathrm{g}}$ for epoxy-rubber blend is slightly higher by $1^{\circ}$, compared to the neat epoxy. The presence of PMMA, grafted to rubber particles could increase the $\mathrm{T}_{\mathrm{g}}$. Meanwhile, the addition of 5 phr cloisite $30 \mathrm{~B}$ in epoxy does not affect the $\mathrm{T}_{\mathrm{g}}$ of resulted nanocomposite. The ternary system seems to show great improvement in $\mathrm{T}_{\mathrm{g}}$ with the difference about $5^{\circ} \mathrm{C}$, compared to neat epoxy.

Figure 3 demonstrates the onset of $\mathrm{T}_{\mathrm{g}}$ for samples cured at $40^{\circ} \mathrm{C}$ for $20 \mathrm{~h}$ then postcured at $125^{\circ} \mathrm{C}$ for $3 \mathrm{~h}$. Generally, it could be observed that the $\mathrm{T}_{\mathrm{g}}$ was higher by 


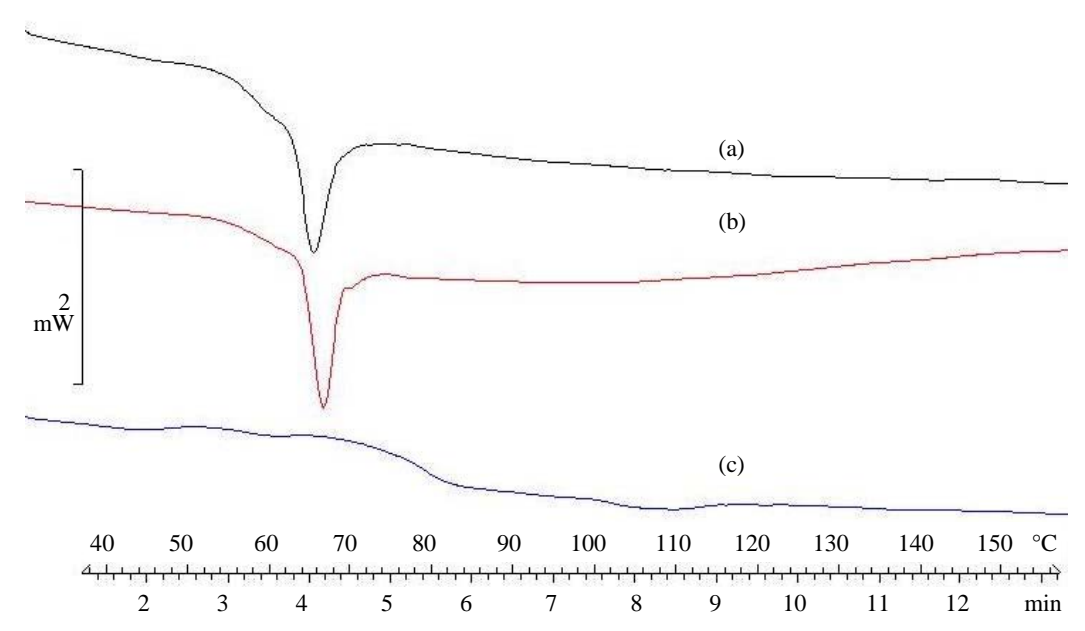

Fig. 1: The DSC graph during the first heating scan for epoxy samples, cured at: a) Room temperature (Yuhana et al., 2012); b) $40^{\circ} \mathrm{C}$ for $20 \mathrm{~h}$ and c) $40^{\circ} \mathrm{C}$ for $20 \mathrm{~h}$ then postcured at $125^{\circ} \mathrm{C}$ for $3 \mathrm{~h}$

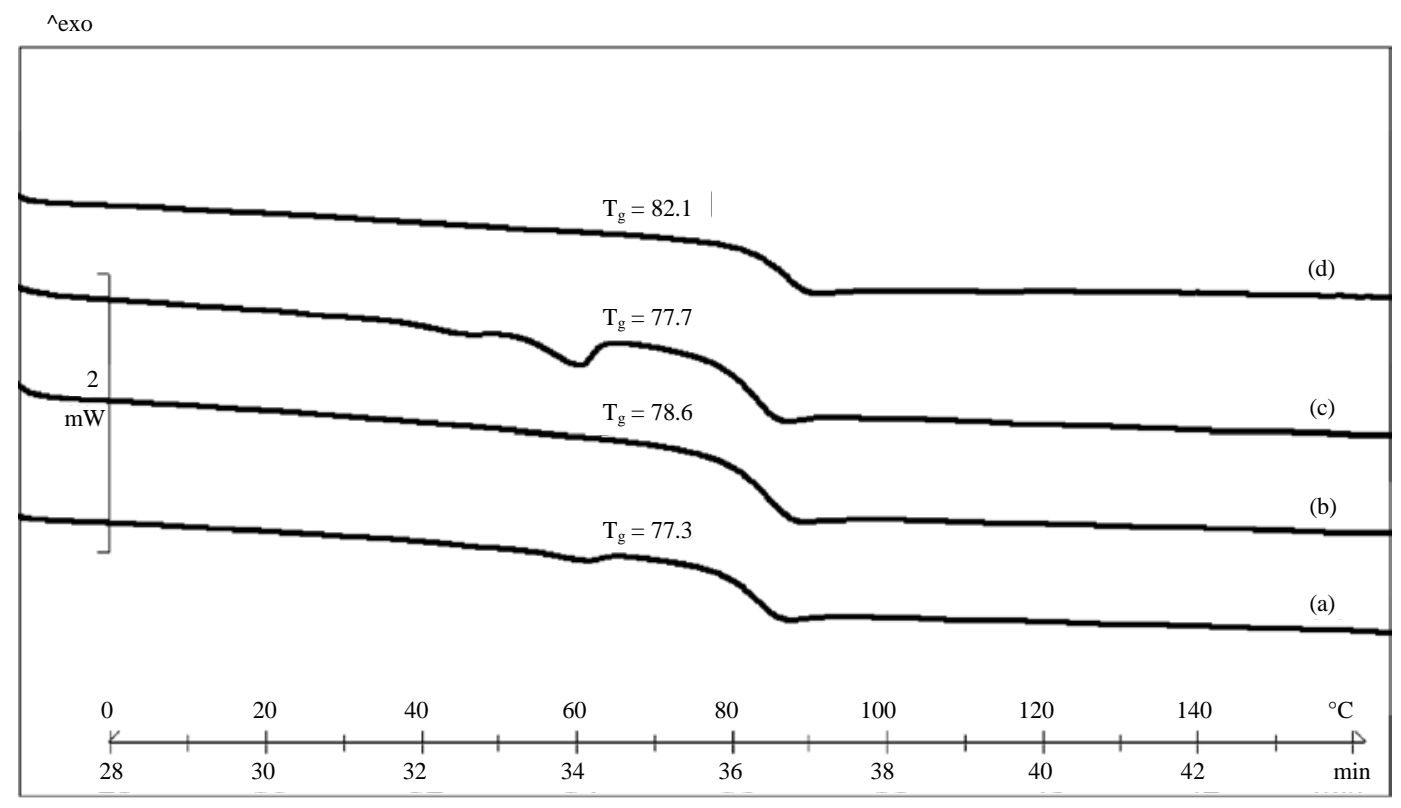

Fig. 2: DSC graph of unpostcured samples of: a) Epoxy; b) Epoxy-5MG30; c) Epoxy-530B and d) Epoxy-5MG30-530B

about $5^{\circ} \mathrm{C}$ compared to the ones which were not postcured, except for epoxy-rubber blend which shows a slightly increase, approximately $2^{\circ} \mathrm{C}$. This may be due to the absence of low molecular weight compound such as reactants and moisture in the samples which may act as plasticizers. The postcured epoxy rubber blend has lower $\mathrm{T}_{\mathrm{g}}$, compared with the postcured neat epoxy. This may be attributable to the rubbery nature of rubber particles which tend to decrease $\mathrm{T}_{\mathrm{g}}$ of the blend. Whether they were postcured or not it seems that addition of $5 \mathrm{phr}$ cloisite 30B does not influence the $\mathrm{T}_{\mathrm{g}}$. However, in the case of rubber modified epoxy clay nanocomposite, the $T_{g}$ was increased by $4-5^{\circ} \mathrm{C}$, compared to the neat epoxy. This suggested that ternary system can possess better thermal stability (Fig. 3).

FTIR: The FTIR spectra of cured samples and epoxy resin are compared in Fig. 4. Two peaks at 830 and $911 \mathrm{~cm}^{-1}$ corresponding to the epoxide ring is observed in the spectrum of epoxy resin liquid. It appears that all cured 


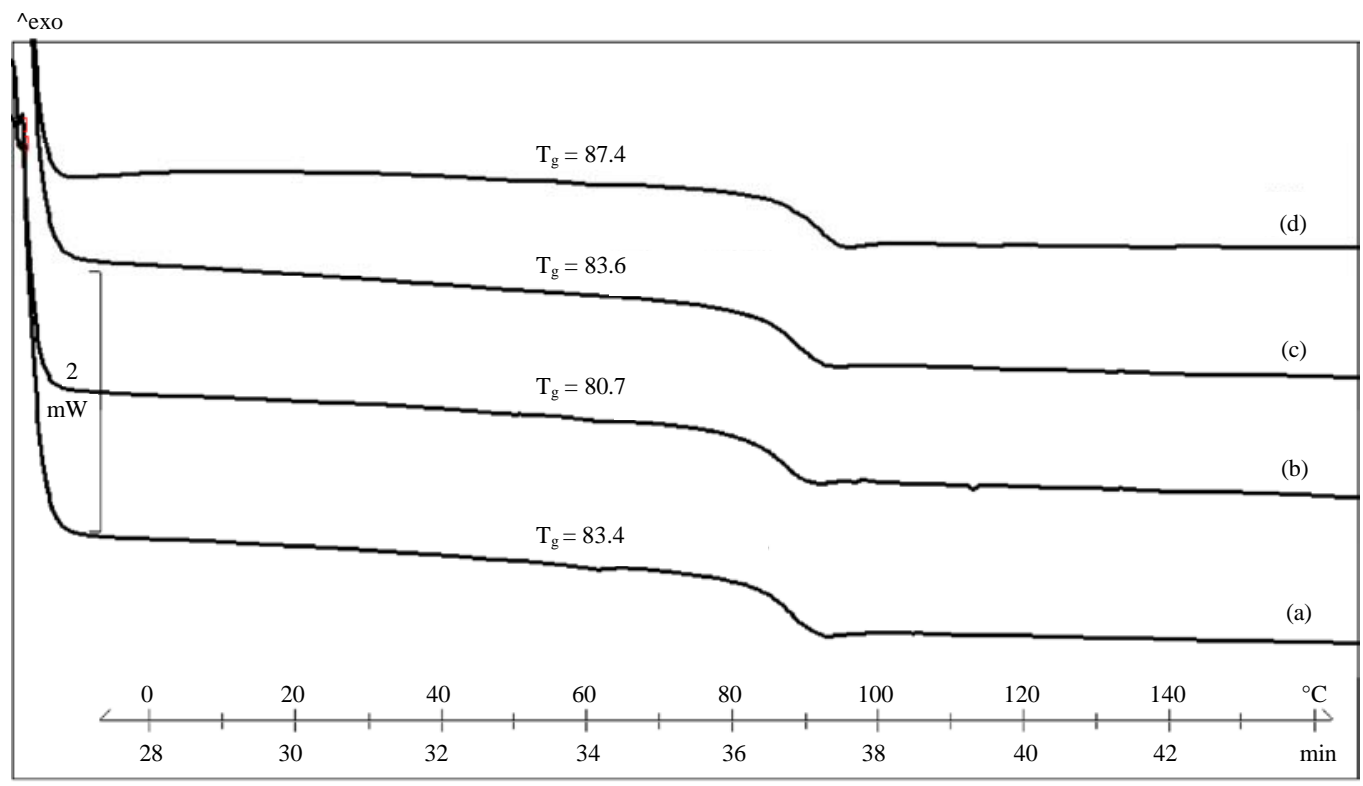

Fig. 3: The DSC graph of postcured samples of: a) Epoxy; b) Epoxy-5MG30; c) Epoxy-530B and d) Epoxy-5MG30-530B
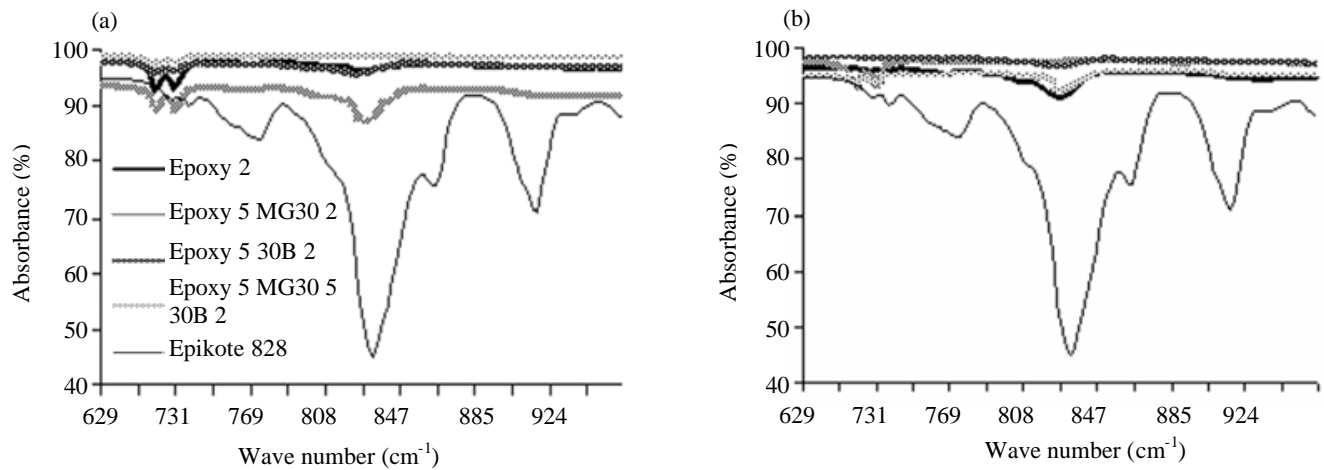

Fig. 4: The FTIR spectra of epoxy liquid resin (Epikote 828) and cured samples for: a) Unpostcured and b) Postcured samples

samples, except the ternary systems indicate a weak peak at $830 \mathrm{~cm}^{-1}$. In the case for postcured samples, the ternary systems together with cured neat epoxy showed the similar peak. The traces of epoxide in the nanocomposite ternary system could be due to the presence of fillers that restrict the chemical reaction between epoxy and curing agent. As for the postcured epoxy, the epoxide ring might be ascribable to thermal degradation of epoxy matrix.

Transmission electron microscopy: The TEM images of postcured samples are given in Fig. 5a, b for epoxy-clay nanocomposites and Fig. 5c, d for rubber toughened epoxy clay nanocomposites. Figure 5 a illustrates the aggregates of clay in the sample and intercalated silicate. No clear exfoliated structure of clay was observed.
Nevertheless, the agglomeration of silicate on rubber particles may reduce the degree of intercalation as shown in Fig. 5 d.

X-ray diffraction: The XRD spectra of cured samples are given in Fig. 6a, b. The cured epoxy is noncrystalline. However, the XRD spectra show the existence of crystalline structure for both postcured and unpostcured epoxy with interlayer spacing about $21 \AA$. This may be due to the crystalline structure of low molecular weight molecules such as the unreacted epoxy, polyetheramine or others. Improved mixing and higher curing temperature may result in a fully cured material. The epoxy/rubber blend spectrum exhibits no sharp peaks in the range $2 \theta=3-10$. The XRD spectrum of epoxy containing $5 \mathrm{phr}$ 

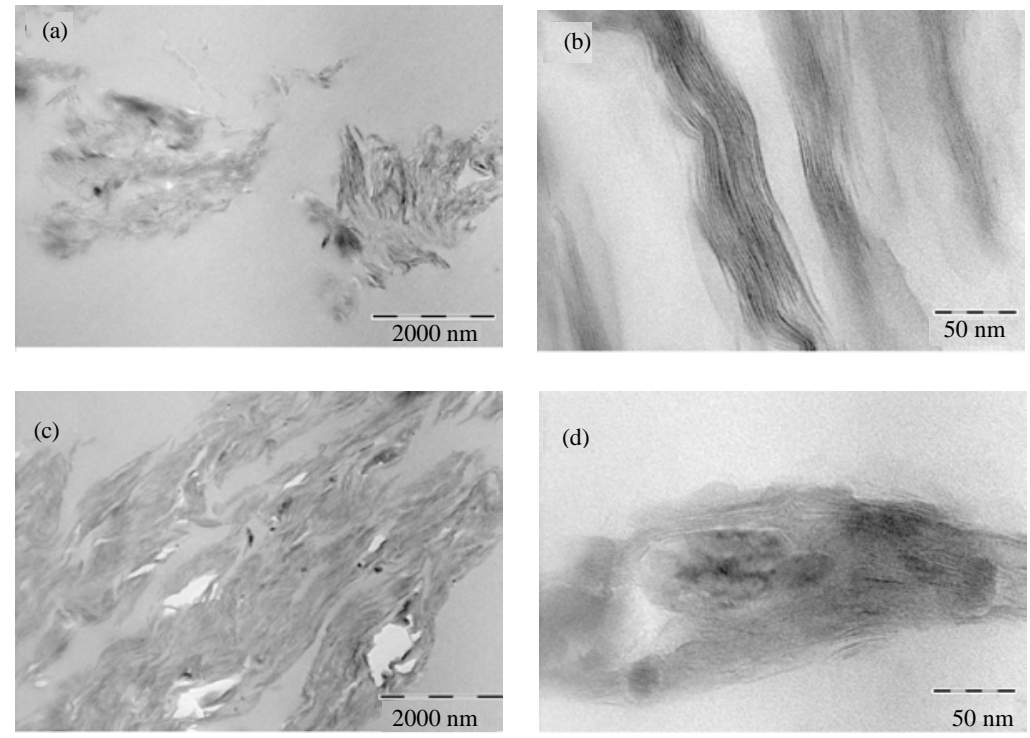

Fig. 5: The TEM images of: a) Aggregates of cloisite 30B in epoxy-5 phr cloisite 30B; b) Intercalated cloisite 30B; c) Aggregates of cloisite $30 \mathrm{~B}$ and rubber particles and d) Cloisite $30 \mathrm{~B}$ silicates are adsorbed on rubber particles. The samples were all postcured

(a)

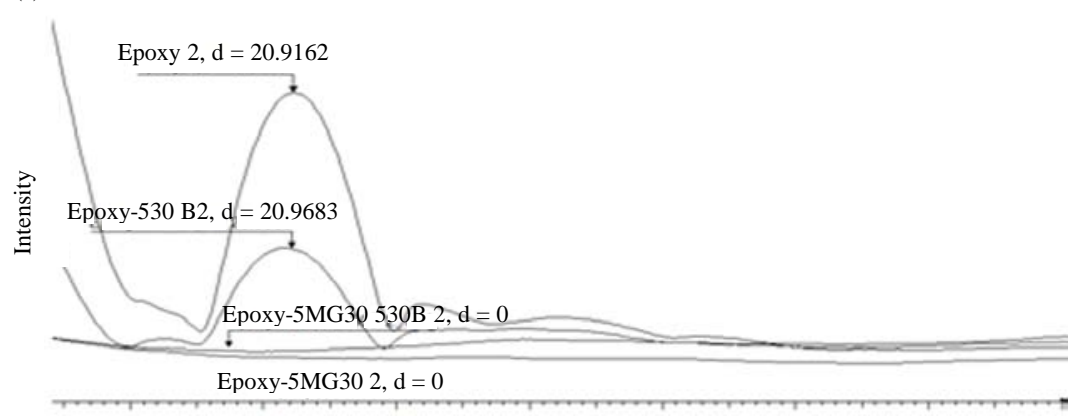

(b)

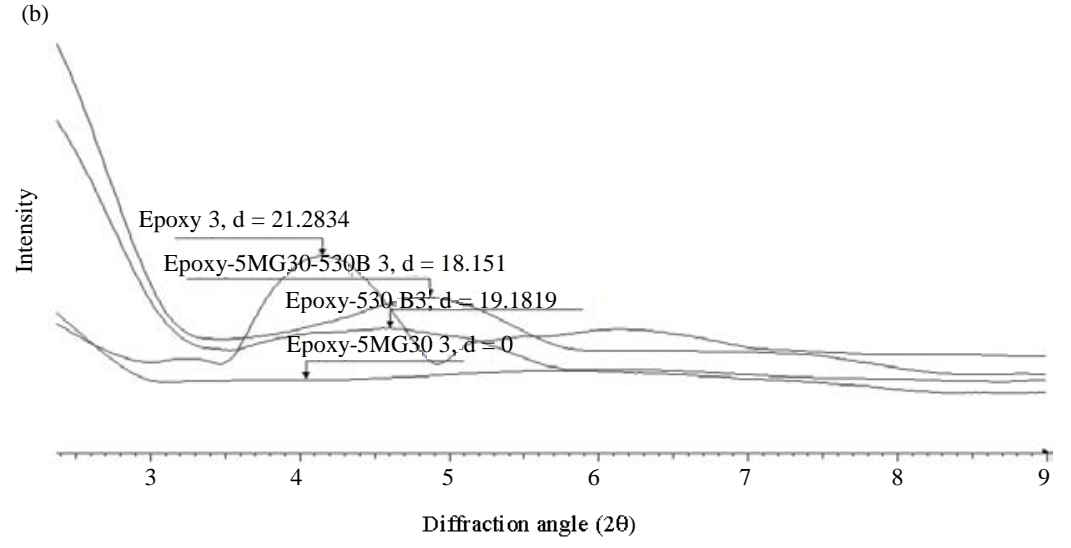

Fig. 6: XRD spectra of cured samples at temperature: a) $40^{\circ} \mathrm{C}$ for $20 \mathrm{~h}$ and b) $40^{\circ} \mathrm{C}$ for $20 \mathrm{~h}$ then postcured at $125^{\circ} \mathrm{C}$ for $3 \mathrm{~h}$ 
cloisite $30 \mathrm{~B}$ shows the existence of crystalline structure for postcured and unpostcured epoxy nanocomposite with interlayer spacing about 21 and $19 \AA$, respectively. It is difficult to conclude that the peak is due to the silicate, since, the neat epoxy spectrum does show a peak near the range.

There is a weak peak in the XRD spectra of postcured epoxy containing $5 \mathrm{phr}$ MG 30 and 5 phr cloisite $30 \mathrm{~B}$ around $2 \theta=4.9^{\circ}\left(\mathrm{d}_{001}=18 \AA\right)$. Nevertheless, for unpostcured ternary systems there is no distinct peak being observed. This may be attributable to the exfoliated clay structure in some points. From the XRD analysis it can be deduced that the intercalated structure of cloisite 30B might exist with interlayer spacing about $18-21 \AA$ in the epoxy matrix in both the absence and presence of rubber particles. Furthermore, the presence of crystalline structure in epoxy is possible, hence, careful analysis of $\mathrm{XRD}$ is needed.

\section{CONCLUSION}

It was observed that the onset of glass transition temperatures is higher, compared to the unpostcured samples. The glass transition of rubber toughened epoxy clay nanocomposite is the highest among the 4 samples for both postcured and unpostcured. This may indicate the suitability of the material to be used at high temperature even in the presence of rubber particles inside the polymer marix. It seems that the presence of cloisite $30 \mathrm{~B}$ aggregates as being observed in TEM image does not reduce the thermal stability and the glass transition significantly. Also, the intercalated structure of silicate in rubber toughened epoxy clay nanocomposite sample may restrict the mobility of epoxy network, hence, increase the onset of $\mathrm{T}_{\mathrm{g}}$. The presence of crystalline structure in epoxy is possible. Therefore, careful analysis of WAXD is needed.

\section{ACKNOWLEDGEMENTS}

The researchers would like to acknowledge help from Ms. Nor Maizana Zakaria from Rubber Research Institute of Malaysia, Ms. Suhaniza Razali and Mr. Ahmad Zaki Zaini from Unit Mikroskopi of Universiti Kebangsaan Malaysia and Mr. Zailan Mohd. Yus of for their kind assistance.

\section{REFERENCES}

Balakrishnan, S. and D. Raghavan, 2004. Acrylic elastomeric particle-dispersed epoxy-clay hybrid nanocomposites: Mechanical properties. Macromol. Rapid Commun., 25: 481-485.

Balakrishnan, S., P.R. Start, D. Raghavan and S.D. Hudson, 2005. The influence of clay and elastomer concentration on the morphology and fracture energy of preformed acrylic rubber dispersed clay filled epoxy nanocomposites. Polym., 46: 11255-11262.

Becker, O. and G.P. Simon, 2005. Epoxy layered Silicate nanocomposite. Adv. Polym. Sci., 179: 29-82.

Becker, O., G.P. Simon and K. Dusek, 2005. Epoxy Layered Silicate Nanocomposites. In: Inorganic Polymeric Nanocomposites and Membranes, Becker, O., B. Boutevin, F. Guida-Pietrasanta, N. Hasegawa and M. Klapper et al (Eds.). Springer, Berlin, Germany, ISBN:978-3-540-25325-9, pp: 29-82.

Becker, O., G.P. Simon, R.J. Varley and P.J. Halley, 2003. Layered silicate nanocomposites based on various high-functionality epoxy resins: The influence of an organoclay on resin cure. Polym. Eng. Sci., 43: 850-862.

Callister, Jr. W.D., D. William and W.D. Callister, 2007. Material Science and Engineering. 7th Edn., John Wiley and Sons, Hoboken, New Jersey, USA., ISBN-13:978-0470054888,

Frohlich, J., R. Thomann, O. Gryshchuk, J. Karger-Kocsis and R. Mulhaupt, 2004. High-performance epoxy hybrid nanocomposites containing organophilic layered silicates and compatibilized liquid rubber. J. Appl. Polym. Sci., 92: 3088-3096.

Kinloch, A.J. and A.C. Taylor, 2003. Mechanical and fracture properties of epoxy/inorganic micro and nano-composites. J. Mater. Sci. Lett., 22: 1439-1441.

Liu, W., S.V. Hoa and M. Pugh, 2004. Morphology and performance of epoxy nanocomposites modified with organoclay and rubber. Polym. Eng. Sci., 44: 1178-1186.

Ratna, D., O. Becker, R. Krishnamurthy, G.P. Simon and R.J. Varley, 2003. Nanocomposites based on a combination of epoxy resin, hyperbranched epoxy and a layered silicate. Polym., 44: 7449-7457.

Yuhana, N.Y., S. Ahmad, M.R. Kamal, S.C. Jana and A.R.S. Bahri, 2012. Transmission electron microscopy study of room temperature cured PMMA grafted natural rubber toughened epoxy/layered silicate nanocomposite. Plast. Rubber Compos., 41 : 390-395. 